\title{
Cord Blood High Density Lipoproteins: Leningrad and Cincinnati*
}

\author{
ANATOLI N. KLIMOV, CHARLES J. GLUECK, ${ }^{(34)}$ PETER S. GARTSIDE, EUGENIA JA. \\ MAGRACHEVA, MARGARET JA. LIVTCHAK, DMITRI B. SHESTOV, DAVID W. ANDERSON, \\ REGINALD C. TSANG, EVAN A. STEIN, AND PAULA M. STEINER \\ Departmenis of Medicine, Pediatrics, and Pathology; Lipoprotein Research Laboratory, Generat Clinical Research \\ Center, and Lipid Research Clinic, University of Cincinnati, College of Medicine (C.J.G., P.S.G., R.C.S., E.A.S., \\ P.M.S.), Cincinnati, Ohio, USA. Anitchkov Department of Atherosclerosis, and the Lipid Research Clinic, The \\ Leningrad Institute of Experimental Medicine (A.N.K., E.Ja.M., M.Ja.L., D.B.S.), Leningrad, USSR; Donner \\ Laboratory, University of California (D.W.A), Berkeley, Colifornia, USA
}

\begin{abstract}
Summary
Adult Russian males (ages $40-49$ ) have recently been shown, in collaborative Lipid Research Clinic (LRC) studies, to have substantially higher $(8-10 \mathrm{mg} / \mathrm{dl})$ plasma high-density lipoprotein cholesterol (C-HDL) than adult American males. Since C-HDL has a powerful inverse correlation with the risk of developing coronary heart disease, elucidation of the etiology of cross-cultural differences in C-HDL may be important in developing approaches to prevent or ameliorate coronary heart disease. This LRC study, using identically standardized LRC laboratories, focused on cord blood C-HDL in 423 neonates of Leningrad (USSR) and 425 neonates of Cincinnati (USA) to determine whether, like Russian adults, Russian neonates had higher C-HDL levels. Mean C-HDL levels in male and female American neonates were slightly (1-2 $\mathrm{mg} / \mathrm{dl})$, but not significantly higher $(P=0.22,0.22)$ than in male and fenuale Russian neonates, respectively. In subsets of the neonate American (260 of 425) and Russian (174 of 423) groups, mean C-HDL levels were $3 \mathrm{mg} / \mathrm{dl}$ and $3 \mathrm{mg} / \mathrm{dl}$ higher, respectively,

* This investigation was supported in part by NHLB1 Lipid Research Clinic's Contract NOI HV 2-2914 L (Cincinnati), and by the collaborative USSR-USA Lipid Research Clinics. A portion of this work was supported by the General Clinical Research Center Grant RR00068-15.
\end{abstract}

in male and female American neonates than in their Russian counterparts, and these small mean differences were statistically signiffcant, $P<0.025$. Thus, adult Russian-American differences in C-HDL were not echoed by comparisons of neonates, using identical laboratory methods for lipoprotein determination. The within-culture, cross-sex comparisons of cord blood lipids and lipoproteins, did, however, parallel findings in older children and young adults. Both female American and Russian meonates had higher $C$-HDL levels than did males $(P=0.001,0.002)$. Within the limits of inheritance as expressed by cord blood lipoproteins, the dichotomy between Russian and American neonates and adults for C-HDL suggests that higher adult Russian C-HDL levels may possibly rehect an aggregate of variables grouped under the term "environmental effect."

\section{Speculation}

Because population studies and studies of kindreds with familial hyper- $\alpha$-lipoproteinemia reveal a strong inverse correlation of $\mathbf{C}$ HDL with coronary heart disease, the elucidation of the etiology of cross-cultural and cross-racial differences in C-HDL might have considerable importance in identifying "protective" environmental differences relevant to development of coronary heart disease. 